\title{
POSTHUMANISMO. CONTORNOS DE UNA HERRAMIENTA EPISTEMOLÓGICA (I)
}

\section{POSTHUMANISM. OUTLINES OF AN EPISTEMOLOGICAL TOOL (I)}

\author{
Carlos Tello \\ Université de Paris / Université Paris-Est Créteil
}

\section{ABSTRACT}

The present is a theoretical text interested in the arrival of post-humanism in the epistemological field in the last years of the 20th century. It talks about two critical speeches on humanism, the first by Friedrich Nietzsche and the second by Michel Foucault, to later find in the German philosopher Peter Sloterdijk's lecture, Rules for the Human Park, in 1997, a kind of birth certificate of post-humanism as a philosophical question. A definition of posthumanism is proposed below through six discourses that constitute a system, and that open up as an epistemological perspective for the study, mainly, of literature and cinema.

This article is the first of two, the second will be an analysis of literary and cinematographic works in light of these post-humanist discourses.

Key words: post-humanism, epistemology, philosophy, literary theory, cinema. 


\section{RESUMEN}

El presente es un texto teórico que se interesa por la llegada del posthumanismo al campo epistemológico en los últimos años del siglo XX. Rastrea dos discursos críticos sobre el humanismo, el primero de Friedrich Nietzsche y el segundo de Michel Foucault, para luego encontrar en la conferencia del filósofo alemán Peter Sloterdijk, Normas para el parque bumano, de 1997, una suerte de acta de nacimiento del posthumanismo en tanto cuestión filosófica. Se propone a continuación una definición del posthumanismo a través de seis discursos que componen un sistema, y que se abren como una perspectiva epistemológica para el estudio, principalmente, de la literatura y el cine.

Este artículo es el primero de dos, el segundo será un análisis de obras literarias y cinematográficas a la luz de esos discursos posthumanistas.

Palabras clave: posthumanismo, epistemología, filosofía, teoría literaria, cine.

Fecha de recepción 17 de septiembre de 2020.

Fecha de aceptación: 12 de octubre de 2020.

Cómo citar: Tello, Carlos (2020), «Posthumanismo. Contornos de una herramienta epistemológica», en Actio Nova: Revista de Teoría de la Literatura y Literatura Comparada, 4: 439463.

DOI: https://doi.org/10.15366/actionova2020.4.019 
Como en el cuento «Tlön, Uqbar, Orbis Tertius» de Jorge Luis Borges, donde el descubrimiento de una ciudad fantástica se debe a la conjunción de dos elementos sin relación aparente, un espejo y una enciclopedia ${ }^{1}$, el nacimiento del posthumanismo como herramienta epistemológica, puede fecharse en 1997 gracias a dos conjunciones paralelas: la publicación de dos escritos de naturaleza diferente y las reacciones que suscitaron.

La primera conjunción es la de la publicación en 1997 de la novela Night Train [Tren nocturno] del escritor inglés Martin Amis (1949-), y el comentario que la obra mereció al escritor estadounidense John Updike (1932-2009). La novela cuenta la inútil búsqueda de un motivo o de un culpable por la muerte de la joven astrofísica Jennifer Rockwell, quien a pesar de su felicidad aparente, de sus favorables condiciones económicas, sociales y sentimentales, de su belleza y de su inteligencia, se suicidó de tres tiros en la cabeza. John Updike, en su comentario titulado «On the Edge of the Post-human», afirma:

En Tren nocturno [Martin Amis] nos hace ver de cerca una autopsia e ilumina el vacío, no solamente el vacío moral a nuestro alrededor $[\ldots]$, sino el de los fenómenos astronómicos como los agujeros negros, la materia negra y el vacío de Bootes ${ }^{2}$. [...] Antes de abrir las válvulas de lágrimas autodestructoras, la detective Hoolihan especula: "a veces pienso que Jennifer vino del futuro".

Los jóvenes, me dijeron el verano pasado en Italia, ya no hablan de posmoderno sino de posthumano. Para afrontar el futuro, se inclinan por la mutilación y las partes artificiales del cuerpo. Amis escribe desde una sensibilidad incómodamente situada en el límite de lo posthumano. Sorprendentemente sus personajes carecen del alma y del calor que admira en Saul Bellow; se ven como autómatas acelerados, como un conjunto de rasgos (a menudo desagradables). No es de extrañar que lo poco que puede hacer con ellos es acabarlos. Su ficción carece de lo que la difunta Queenie Leavis llamaba 'positivos'. Como misterio, Tren nocturno adolece de la ausencia de personajes menores lo suficientemente simpáticos para procurar siquiera una pista falsa. Podemos creer, al menos inicialmente, en la jerga de Mike Hoolihan y en su amor blues por el trabajo policial; no podemos creer en nada de Jennifer Rockwell, sino en su cuerpo supuestamente hermoso y ahora vacío. Ella, y Tren nocturno, se convierten en un diagrama de poros en una pizarra tan plana como negra. ${ }^{3}$

\footnotetext{
${ }^{1}$ El cuento se abre con la frase siguiente: «Debo a la conjunción de un espejo y de una enciclopedia el descubrimiento de Uqbar» (91).

2 Descubierto en 1981, el Boötes Void en inglés, llamado en español Gran vacío o vacío de Bootes, designa una región del espacio intergaláctico de gran tamaño en la que se encuentran pocas galaxias. Constituye uno de los más grandes vacíos conocidos.

3 «In Night Train [Martin Amis] makes us closely watch an autopsy and spotlights the void, not just the moral void around us [...] but astronomical phenomena like black holes, the missing dark matter, and the Boötes Void. [...] Detective Hoolihan, before going off on a self-destructive tears, speculates, "I sometimes think that Jennifer Rockwell came from the future." Young people, I was told last summer in Italy, are talking no longer about the postmodern but the post-human. To keep up with the future, they are going in for mutilation and artificial body parts. Amis writes out of a sensibility uncomfortably on the edge of the post-human. His characters strikingly lack the soulful, willful warmth that he admires in Saul Bellow; they seem quick-moving automata, assembled of (mostly disagreeable) traits. No wonder he can think of little to do with them but finish
} 
Lo que John Updike encuentra problemático en Tren nocturno es la solución del misterio y el objetivo mismo de la novela. La indiferencia y la frialdad de los personajes de Martin Amis son percibidos por el escritor americano como una pérdida, como un abandono. Es el caso del personaje de Jennifer Rockwell, terriblemente vacío, que parece más cercano a una máquina, a un autómata o, como se sugiere en la novela, a un ser venido del futuro, que a un ser humano. Es en ese contexto que la noción de «posthumano» es utilizada, con dos alusiones importantes. La primera, lo posthumano aparece relacionado con lo posmoderno, como aquello que lo remplaza o que lo sucede. La segunda, lo posthumano implica, simultáneamente, una oposición y una transgresión. La oposición es aquella entre una concepción de lo humano como racional y afectivo, lógico y expresivo, y el personaje de Jennifer Rockwell, que se muestra indiferente, insensible e irracional. La transgresión, por su parte, es la de los límites del cuerpo humano.

Sin embargo, en Tren nocturno no hay realmente transformaciones físicas, ni mutilaciones ni partes artificiales del cuerpo. No hay, tampoco, verdaderos autómatas. Si John Updike introduce esos términos es porque ha identificado un paralelo entre, por una parte, las posibilidades técnicas y científicas de transformación del cuerpo, y, por otra, el abandono de una representación sicológica e incluso moral del ser humano. A través de esas dos alusiones, lo posthumano es presentado como una manera de expresar el malestar de una época, se trata, entonces, de una perspectiva artística, literaria.

La segunda conjunción que permite establecer la fecha de nacimiento del posthumanismo no es literaria sino filosófica. La conferencia Regeln für den Menschenpark. Ein Antwortschreiben zu Heideggers Brief über den Humanismusis.ip: Normas para el parque humano. Una respuesta a la Carta sobre el humanismo de Heidegger] del filósofo alemán Peter Sloterdijk (1947) fue pronunciada primero en Basilea en 1997, y luego, dos años más tarde, en el marco de un coloquio sobre los filósofos Martin Heidegger y Emmanuel Levinas. Una vez publicada, la conferencia constituye une suerte de introducción oficial de la cuestión del posthumanismo en Europa, principalmente en Alemania y Francia. Sloterdijk abordaba la crítica al humanismo de Heidegger a partir de su Brief über den Humanismus [Carta sobre el humanismo] de

them off. His fiction lacks what the late Queenie Leavis called 'positives'. As a mystery Night Train suffers from a lack of minor characters even momentarily sympathetic enough to serve as red herrings. We can believe, initially at least, in Mike Hoolihan's slangy way of talking and her bluesy love of police work; we can't believe in anything about Jennifer Rockwell but her supposedly beautiful and now vacated body. She, and Night Train, become pore diagram, on a blackboard as flat as it is black». La traducción es mía. 
1947, afirmaba su legitimidad pero proponía igualmente una superación crítica de su ontología, que juzgaba aún metafísica. La filosofía propuesta por Sloterdijk busca dar cuenta del hecho de que el ser humano no puede ser considerado como un animal racional, civilizado - en eso está de acuerdo con Heidegger -, sino como una nueva forma de ser, resultado de los avances de la ciencia y la tecnología. Por ello Sloterdijk califica de posthumanista [post-humanistisch] la profunda transformación social en curso. Dos ideas principales de esa conferencia permiten establecer los contornos del posthumanismo. La primera, la humanidad del ser humano debe ser comprendida como la consecuencia de un proceso de crianza y domesticación, de una forma de selección; la segunda, es necesario establecer un código para los métodos actuales de crianza y domesticación, el código de una antropotécnica.

Normas para elparque bumano generó una polémica en Alemania y en Francia bajo en nombre de affaire Sloterdijk. Aunque no faltaron las evocaciones al partido Nazi y sus experimentaciones eugenésicas, el mérito del texto de Sloterdijk es el de haber suscitado un debate filosófico sobre las biotecnologías y su relación con la evolución humana. Si la definición del ser humano dada por el humanismo clásico ya había sido criticada, si el humano ya había sido presentado como un ser fabricado, sujeto a fuerzas y principios que lo exceden, como el producto de un proceso del que él es, al mismo tiempo y de manera consciente o inconsciente, autor y responsable (Karl Marx, Sigmund Freud), el posthumanismo se distingue porque supone una transformación radical, irreversible y voluntaria de la humanidad.

Sin embargo, para comprender plenamente la proposición de Sloterdijk y las críticas que alimentaron el affaire, es necesario inscribir las dos en la historia de las numerosas discusiones sobre el humanismo, más allá del texto de Heidegger. Antes de volver a Sloterdijk y a la cuestión de la biotecnología, es importante señalar dos momentos decisivos de la crítica al humanismo en Europa, encabezados por Friedrich Nietzsche (1844-1900) y Michel Foucault (1926-1984), quienes describen y fechan de maneras diferentes el fenómeno.

\section{Nietzsche}

En su segunda obra, Über Warheit und Lüge im außermoralischen Sinn [Sobre verdady mentira en sentido extramoral, escrita en 1873, Nietzsche desarrollaba su crítica al antropocentrismo humanista a través de una fábula: 
En algún apartado rincón del universo centelleante, desparramado en innumerables sistemas solares, hubo una vez un astro en el que animales inteligentes inventaron el conocimiento. Fue el minuto más altanero y falaz de la "Historia Universal": pero, a fin de cuentas, sólo un minuto. Tras breves respiraciones de la naturaleza, el astro se heló y los animales inteligentes hubieron de perecer. Alguien podría inventar una fábula semejante pero, con todo, no habría ilustrado suficientemente cuán lastimoso, cuán sombrío y caduco, cuán estéril y arbitrario es el estado en el que se presenta el intelecto humano dentro de la naturaleza. Hubo eternidades en las que no existía; cuando de nuevo se acabe todo para él no habrá sucedido nada. (17)

Si en su crítica Nietzsche se proponía un cuestionamiento irónico del «intelecto humano» y de la «invención del conocimiento», si buscaba, además, la posición justa del ser humano en el mundo - sin el fondo metafísico de su obra precedente $-{ }^{4}$, no lo reducía, sin embargo, al animal. En esta fábula, el ser humano conserva una posición excepcional, ya que es capaz de producir conceptos y de utilizar la función biológica que es su intelecto como un «medio de conservación del individuo» ${ }^{5}$. Más tarde, en un pasaje célebre de Also Sprach Zarathoustra. Ein Buch für Alle und Keinen [Así habló Zaratustra. Un libro para todos y para nadie], de 1885, el ser humano es comprendido como un momento y no como una finalidad, como «una cuerda tendida entre el animal y el superhombre» (38). El camino que recorre el espíritu humano de un punto al otro está marcado por tres instantes de transformación, tres metamorfosis:

Tres transformaciones del espíritu os menciono: cómo el espíritu se convierte en camello, y el camello en león, y el león, por fin, en niño.

Hay muchas cosas pesadas para el espíritu, para el espíritu fuerte, de carga, en el que habita la veneración: su fortaleza demanda cosas pesadas, e incluso las más pesadas de todas. [...]

Con todas esas cosas, las más pesadas de todas, carga el espíritu de carga: semejante al camello que corre al desierto con su carga, así corre él al desierto.

Pero en lo más solitario del desierto tiene lugar la segunda transformación: en león se transforma aquí el espíritu, quiere conquistar su libertad como se conquista una presa y ser señor en su propio desierto [...].

"Tu debes" le cierra el paso, brilla como el oro, es un animal escamoso, y en cada una de sus escamas brilla áureamente " $¡ T u$ debes!” [...]

Crear valores nuevos - tampoco el león es aún capaz de hacerlo: mas crearse libertad para un nuevo crear - eso sí es capaz de hacerlo el poder del león.

Crearse libertad y un no santo incluso frente al deber: para ello, hermanos míos, es preciso el león $[\ldots]$.

Inocencia es el niño, y olvido, un nuevo comienzo, un juego, una rueda que se mueve por sí misma, un primer movimiento, un santo decir sí.

Sí, hermanos míos, para el juego del crear se precisa un santo decir sí: el espíritu quiere ahora $s u$ voluntad, el retirado del mundo conquista ahora $s u$ mundo. (5355)

\footnotetext{
${ }^{4}$ Ver: El nacimiento de la tragedia o Grecia y el pesimismo (1872).

5 Sobre verdad y mentira en sentido extramoral (18).
} 
Para Nietzsche, hablar del ser humano es hablar, a través de la fábula o la metáfora, de su prehistoria mítica y de su futuro. No es entonces un objetivo sino un puente. En lo que se refiere al superhombre, que se encuentra al final de ese puente, es el espíritu convertido en niño, que ha recuperado su inocencia y disfruta de su libertad, que es dueño de sí mismo. La misión del humano, si tiene una, es la de no retornar hacia la bestia, sino de superarse, alejarse del gusano, del mono, para alcanzar un estado superior. El ser humano debe tener en mente al superhombre, y pensar en la manera en la que será visto por él ${ }^{6}$. Nietzsche escribe para aquellos que no quieren mirar atrás, sino más allá de todos. Para lograr tal visión, deben ser expulsados de su propio país, abandonar sus ancestros, dejar atrás a sus padres y abrirse al país de sus hijos, todavía inexistente, inexplorado, pero símbolo de la búsqueda infatigable. Ese horizonte, inalcanzable por definición, hace del superhombre de Nietzsche, como del humano, más un estado de ánimo que un ser concreto.

Si tanto Zaratustra como Nietzsche hacen un llamado a convertirse en progenitor, en criador, sembrador del futuro, esas tareas parecen ser ocupadas por los sacerdotes y por los profesores. Nietzsche ve esos oficios como los vectores del humanismo, es decir de los valores y de la moral tradicionales, en el sentido en que buscan la igualdad y la domesticación de los instintos y de las pulsiones de rebelión. Se abre entonces, según el filósofo, una lucha sin tregua entre los criadores de las «gentes pequeñas» (391) y los del superhombre.

Es en ese mismo campo de batalla que más tarde tendrá lugar la discusión sobre la antropotécnica $^{7}$, cuyas prácticas comprenden el aumento de la fuerza (dopajes, modificaciones genéticas), agudización de la inteligencia (sicoestimulantes, implantes de memoria), control de la procreación (anticoncepción, antigestación, elección de características de los bebés), variación de la sexualidad (afrodisiacos o antilíbidos, modificación del sexo), modificaciones estéticas (cirugía estética, moda corporal) y alteración de las emociones (sicótropos del humor) ${ }^{8}$.

\footnotetext{
${ }^{6}$ «Todos los seres han creado hasta ahora algo por encima de sí mismos: ¿y queréis ser vosotros el reflujo de ese gran flujo y retroceder al animal más bien que superar al hombre? ¿Qué es el mono para el hombre? Una irrisión o una vergüenza dolorosa. Habéis recorrido el camino que lleva desde el gusano hasta el hombre, y muchas cosas en vosotros continúan siendo gusano. En otro tiempo fuisteis monos, y también ahora es el hombre más mono que cualquier mono» (36).

${ }^{7} \mathrm{La}$ antropotécnica se puede definir como el arte o la técnica de transformación extramedical del ser humano por la intervención sobre su cuerpo. Ver: Jérôme Goffette, «Anthropotecnie (ou anthropotechnique) et Human Enhancement», in Gilbert Hottois, Jean-Noel Missa y Laurence Perbal (dir.). L’bumain et ses préfixes. Encyclopédie du transhumanisme et du posthumanisme, 2015 (18).

8 Ibid. (21).
} 


\section{Foucault}

En la segunda mitad del siglo Xx, en Francia, la crítica formulada por Michel Foucault se concentraba primero sobre la definición misma del humanismo y sobre su periodización. En una entrevista publicada en 1966 afirmaba:

En la enseñanza secundaria aprendemos que el siglo XVI fue la época del humanismo, que el clasicismo desarrolló los grandes temas de la naturaleza humana, que el siglo XVIII creó las ciencias positivas y que nos fue dado entonces conocer al hombre de manera positiva, científica y racional, con la biología, la sicología y la sociología. Imaginamos que el humanismo fue tanto la fuerza fundamental que animó nuestro desarrollo histórico, como la recompensa por ese desarrollo, en otras palabras, que él es su principio y su final. Lo que nos asombra de nuestra cultura es que pueda preocuparse por lo humano. Y cuando hablamos de la barbarie contemporánea, lo hacemos refiriéndonos a las máquinas, o a ciertas instituciones que nos parecen no-humanas.

Todo aquello es una ilusión. Primero, el movimiento humanista data del final del siglo XIX. Segundo, cuando se observan de cerca las culturas de los siglos XVI, XVII y XVIII, es claro que el hombre está, literalmente, ausente. La cultura estaba ocupada por Dios, por el mundo, por la semejanza de las cosas, por las leyes del espacio, ciertamente también por el cuerpo, por las pasiones, por la imaginación. Pero el hombre, él, estuvo completamente ausente. ${ }^{9}$

En Les Mots et les Choses [Las palabras y las cosas], publicado el mismo año, poco antes de la entrevista, Foucault mostraba la composición del hombre como un objeto de estudio, del final del siglo XVIII al inicio del siglo XIX. Su propósito era señalar la modernidad del ser humano e insistir en el hecho de que no fue una problemática moral la que llevó a interesarse por el humano, a conocerlo científicamente, sino su construcción misma la que le había permitido desarrollar temas morales. Tras haber demostrado la coherencia en la época clásica «entre la teoría de la representación y las del lenguaje, de los órdenes naturales, de la riqueza y del valon» (8), y la negatividad en el episteme ${ }^{10}$ clásico de las formas que son el cuerpo, la necesidad, el lenguaje, así como su «conocimiento limitado» ${ }^{11}$, Foucault situaba el cambio de

\footnotetext{
9 «L'homme est-il mort?», 1966 (568). La traducción es mía.

${ }^{10}$ Michel Foucault explica: «No se tratará de conocimientos descritos en su progreso hacia una objetividad en la que, al fin, puede reconocerse nuestra ciencia actual; lo que se intentará sacar a luz es el campo epistemológico, la episteme en la que los conocimientos, considerados fuera de cualquier criterio que se refiera a su valor racional o a sus formas objetivas, hunden su posibilidad y manifiestan así una historia que no es la de su perfección creciente, sino la de sus condiciones de posibilidad; en este texto lo que debe aparecer son, dentro del espacio del saber, las configuraciones que han dado lugar a las diversas formas del conocimiento empírico». Las palabras y las cosas (7).

11 «Para el pensamiento clásico, la finitud (como determinación positivamente constituida a partir de lo infinito) da cuenta de esas formas negativas que son el cuerpo, la necesidad, el lenguaje y el conocimiento limitado que de ellas puede tenerse; para el pensamiento moderno, la positividad de la vida, de la producción y del trabajo (que tienen su existencia, su historicidad y sus leyes propias) fundamente como su correlación negativa el carácter limitado del conocimiento; y a la inversa, los límites del conocimiento fundamentan positivamente la
} 
esta configuración en el siglo XIX. Así, en el episteme moderno, la representación ya no es el fundamento de los órdenes posibles, el discurso desaparece como elemento obligado entre la representación y los seres, el estudio del organismo se impone al de los caracteres taxonómicos, el de la producción al análisis de la moneda. Esta triple transformación marca la entrada del hombre en el saber.

Cuando la historia natural se convierte en biología, cuando el análisis de la riqueza se convierte en economía, cuando, sobre todo, la reflexión sobre el lenguaje se hace filología y se borra este discurso clásico en el que el ser y la representación encontraban su lugar común, entonces, en el movimiento profundo de tal mutación arqueológica, aparece el hombre con su posición ambigua de objeto de un saber y de sujeto que conoce. (303-304)

Foucault afirma entonces que el humanismo y el ser humano fueron producidos en el episteme moderno en el curso del siglo XIX. En la epistemología propuesta en Las palabras y las cosas, el humano es menos un ser que un procedimiento, una manera - que se puede fechar históricamente - de conectar los conocimientos, una organización particular de los contenidos del saber. El pensamiento de Foucault, su arqueología del nacimiento del ser humano y del humanismo, dibujan simultáneamente la finitud del humano y del humanismo, y la llegada de una nueva episteme.

\section{Sloterdijk}

En Normas para el parque bumano, Peter Sloterdijk respondía a la Carta sobre el bumanismo de Martin Heidegger, aparecida veinte años antes de Las palabras y las cosas. Con ese texto, de 1946, se había abierto en Alemania un nuevo periodo de crítica del humanismo. Sloterdijk explica la posición de Heidegger, y su «estrategia», en lo que se refiere al uso de la palabra «humanismo»:

Es preciso abandonar la palabra 'humanismo' si es que ha de recuperarse en su inicial simplicidad e ineludibilidad la verdadera tarea del pensar, que en la tradición humanística o metafísica pretendía darse ya por resuelta. Dicho con más perspicacia: ¿para qué volver a ensalzar al hombre y a su autorrepresentación ejemplar filosófica en el humanismo como la solución, si precisamente en la catástrofe presente se ha demostrado que el propio hombre, con todos sus sistemas de autosobreelevación y autoexplicación metafísica, es el verdadero problema? (40)

posibilidad de saber, pero siempre en una experiencia limitada, lo que son la vida, el trabajo y el lenguaje». Ibid. (308). 
Por su parte, la crítica de Sloterdijk se elaboró en torno a la imagen de la «domesticación» del ser humano, a partir de una historia crítica interpretativa del humanismo europeo. Su conferencia se abre con esta explicación:

Como dijo una vez el poeta Jean Paul, los libros son voluminosas cartas para los amigos. Con esta frase estaba llamando por su nombre, tersa y quintaesencialmente, a lo que constituye la esencia y función del humanismo: humanismo es telecomunicación fundadora de amistades que se realiza en medio del lenguaje escrito. Eso que desde la época de Cicerón venimos denominando bumanitas es, tanto en su sentido más estricto como en el más amplio, una de las consecuencias de la alfabetización. Desde que existe como género literario, la filosofía recluta a sus adeptos escribiendo de manera contagiosa acerca del amor y de la amistad. El hecho de que la filosofía escrita haya podido siquiera mantenerse como un virus contagioso desde sus comienzos hace más de 2.500 años hasta hoy, se lo debe al éxito de esa facilidad suya para hacer amigos a través del texto. [...] El eslabón más importante de esta cadena epistolar fue, sin duda, la recepción del mensaje griego por parte de los romanos, pues la apropiación romana del texto lo hizo por primera vez accesible para todo el imperio e indirectamente también -por encima más allá de la caída de la Roma occidentalpara las culturas europeas posteriores. (19-20)

Sloterdijk presenta el humanismo como la organización social de un tipo de comunicación escrita entre un emisor y un receptor desconocido, que se encuentra a distancia en el tiempo y en el espacio, y que se propone la creación de un vínculo de «amistad». La bumanitas sería el resultado de un proceso iniciado por la alfabetización. Esta forma de transmisión, que comenzó con los griegos y los romanos, que continuó en la cultura occidental y que perdura en la ética «comunicacional» de Jürgen Habermas (1929-), detractor inmediato de la conferencia de Sloterdijk, engendró una estructura social que funciona sobre la base del modelo antiguo de la sociedad literaria, del club o de la secta. El humanismo antiguo tendría por origen una respuesta y una resistencia, una manera de sacar al humano de su estado animal, salvaje, de alejarlo del anfiteatro y de la barbarie, o más simplemente de la ignorancia de las normas «civilizadas» del clan, hacia una «domesticación» que se obtendría gracias a las lecturas adecuadas, las de los autores clásicos. Sin embargo, ese trabajo de civilización humanista fundado en la idea de una sociedad de lectores parece haber fracasado, primero frente al choque producido por la constitución de la cultura de masas al inicio del siglo XX - la llegada de la radio a partir de 1918 y de la televisión a partir de 1945 -; luego, 
en el contexto de la «Sociedad de la información» ${ }^{12}$. Lo anterior revela una oposición entre dos tipos de tendencias entre las que se sitúa el ser humano. Sloterdijk precisa:

El fenómeno del humanismo merece hoy atención sobre todo porque, por mucho que se presente velado y tímido, nos recuerda que en la civilización de la alta cultura los hombres se ven permanentemente reclamados a la vez por dos grandes poderes formativos que, en pro de la simplificación, aquí llamaremos sencillamente influencias inhibidoras y desinhibidoras. Forma parte del credo del humanismo el convencimiento de que los hombres son "animales sometidos a influencia", y que es por ello indispensable hacerles llegar el tipo correcto de influjos. La etiqueta "humanismo" nos recuerda -en su falsa candidez- la perpetua batalla por el hombre que se viene librando en forma de una lucha entre tendencias embrutecedoras y amansadoras. (32-33)

En una entrevista concedida en 2002, Sloterdijk critica los esfuerzos para preservar y transmitir una cultura humanista de tipo clásico - que parece incapaz de organizar las estructuras económicas y políticas de las sociedades contemporáneas - cuando las condiciones de existencia occidentales han sido profundamente transformadas por la sociedad de masas y por la aparición de una tercera cultura, la de los ingenieros:

Estamos en el umbral de un nuevo compromiso de la cultura en el que el humanismo debe saldar sus cuentas con esa tercera cultura de la que nunca se ha ocupado. No se trata ni de las ciencias duras ni de las humanidades, la tercera cultura es aquella de los conocimientos de los ingenieros. Cuando Wilhelm von Humboldt [1767-1835] y algunos otros inventaron la universidad moderna en la época de las guerras napoleónicas -lo que se conoció como neohumanismo prusiano-, hubo entre Francia y Alemania un diálogo de gran envergadura sobre la manera correcta de educar a los seres humanos en esta nueva época. Y la respuesta fue una mezcla de neoclasicismo y de neorrealismo. Hacer las paces entre los eruditos y la tradición clásica, reconciliar al humanismo de Weimar con la cultura de las máquinas, esa fue la lucha cultural del siglo XIX. En el futuro, tendremos una nueva fórmula sólida que reúna los saberes técnicos y la cultura de los ingenieros con esta corriente de base que es la literatura, el primer arte de la escritura. El progreso no viene nunca de la renuncia. Los europeos nunca han olvidado nada. Siempre han integrado nuevas tecnologías en formas cada vez más complejas. ${ }^{13}$

\footnotetext{
${ }^{12}$ En Bruselas, en febrero de 1995, por invitación de la Comisión Europea tuvo lugar la conferencia ministerial sobre la Sociedad de la Información del G7. Participaron representantes de las siete principales potencias económicas: Alemania, Canadá, Estados Unidos, Francia, Italia, Japón y el Reino Unido.

13 «Nous sommes au seuil d'un nouveau compromis de la culture dans lequel l'humanisme traditionnel devra régler ses affaires avec la troisième culture dont il n'a jamais pris acte. Et la troisième culture, ce ne sont ni les sciences dures ni les humanités, mais tous les savoirs des ingénieurs. Lorsque Wilhelm von Humboldt [17671835] et quelques autres ont inventé l'Université moderne à l'époque des guerres napoléoniennes - ce qu'on a appelé le néohumanisme prussien -, il y a eu entre la France et l'Allemagne un dialogue de grande envergure sur la manière dont il fallait éduquer les êtres humains dans cette nouvelle époque. Et la réponse fut un mélange de néoclassicisme et de néoréalisme. Faire la paix entre les savants et la tradition classique, réconcilier l'humanisme de Weimar avec la culture des machines, ce fut la lutte culturelle du XIX ${ }^{\mathrm{e}}$ siècle. Dans l'avenir, nous aurons une nouvelle formule forte qui intègre les savoirs techniques et la culture des ingénieurs à ce courant de base qu'est la littérature, le premier art de l'écriture. Le progrès ne naît jamais du renoncement. Les Européens n'ont jamais rien oublié. Ils ont toujours intégré de nouvelles technologies dans des formes toujours plus complexes». Peter Sloterdijk, «Le scandaleux», 2002. La traducción es mía.
} 
Sloterdijk propone considerar la modernidad maquinista, abordar filosóficamente la no-filosofía, lo que no pertenece al campo filosófico; permitir a lo no humano animar el pensamiento de lo humano. Las relaciones en el mundo actual, señala Sloterdijk, devienen marginalmente literarias, incluso post-literarias, así mismo post-escolares, post-religiosas, post-evolucionistas, post-orgánicas y, por extensión, post-humanistas. Si el humanismo clásico, que tenía por misión la domesticación del ser humano, ha fracasado, ¿cuál es el modelo, y con cuáles herramientas, que podría utilizarse hoy, teniendo en cuenta que es posible realizar esa domesticación por vías diferentes a la educación? ¿No sería necesario escribir un código de las antropotecnologías y prever los procedimientos de una planificación, ya no literaria sino genética? Esas fueron las preguntas, y su pronta comparación con la eugenesia nazi, que dieron nacimiento al affaire Sloterdijk.

\section{Debates en torno a Sloterdijk}

El filósofo Jürgen Habermas, uno de los más importantes representantes de la segunda generación de la Escuela de Fráncfort, defensor de los valores del racionalismo de Kant, se refirió en estos términos a Sloterdijk y su conferencia:

Un puñado de intelectuales ansiosos se aventuran a la adivinación de los residuos del café de un posthumanismo, convertido en naturalismo, pretendiendo atravesar el muro del tiempo - una supuesta "hipermodernidad" contra una "hipermoral" -, para, realmente, revivir los temas ya gastados de una ideología bastante alemana. Afortunadamente, esta "élite" que lamenta la "ilusión igualitaria" y el discurso de justicia no cuenta con una gran capacidad infecciosa. Las fantasías nietzscheanas de esos autopromotores que ven en la "lucha entre quienes practican la crianza humana a pequeña escala y quienes la practican a gran escala" el "conflicto fundamental del futuro", que alientan "las grandes fracciones culturales" a "ejercer el poder selectivo que de hecho ya han conquistado", no han ido, por lo pronto, más allá del espectáculo mediático. ${ }^{14}$

En Francia, el médico y biólogo Henri Atlan expresó su desacuerdo con Sloterdijk y el hecho de que asocia «una cierta historia del humanismo con la escritura» ${ }^{15}$. Para él, Normas

\footnotetext{
14 «Une poignée d'intellectuels en état de manque s'essaie à la divination dans le marc de café d'un posthumanisme viré au naturalisme pour, prétendant franchir le mur du temps - l'"hypermodernité" contre l'"hypermorale" -, relancer à vrai dire les thèmes éculés d'une idéologie très allemande. Fort heureusement, cette "élite" qui fait son deuil de l"cillusion égalitaire" et du discours de justice ne dispose pas d'une large capacité infectieuse. Les fantasmes nietzschéens de ces autopromoteurs qui voient dans la "lutte entre ceux qui pratiquent l'élevage humain à petite échelle et ceux qui la pratiquent à grande échelle" le "conflit fondamental de tout avenir", qui encouragent "les fractions culturelles majeures" à "exercer le pouvoir sélectif qu’ils ont de fait conquis", ne sont pas allés, pour l'heure, au-delà du spectacle médiatique». Jürgen Habermas, L'avenir de la

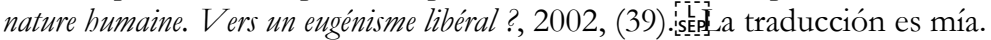

15 «La biologie de demain n’est pas l’eugénisme nazi», 1999. La traducción es mía.
} 
para el parque bumano es una crítica del humanismo clásico pero no abre una nueva vía de reflexión, ya que su autor «confunde los problemas reales que implican las biotecnologías, su interpretación del humanismo, y el problema de la memoria de los alemanes». Atlan expone igualmente la verdadera novedad que según él Sloterdijk parece no haber visto: allí donde este último señalaba una ausencia de sabios y de criadores, en ese proceso de domesticación que denuncia como «sin autor», habría más bien que hablar del mercado, como entidad anónima pero omnipresente que regula el desarrollo de las biotecnologías.

Otros filósofos, entre ellos Bruno Latour (1947-) e Yves Michaud (1944-), se situaron del lado de la defensa de Sloterdijk y denunciaron la debilidad de las acusaciones y sobre todo las malas interpretaciones de su conferencia. Para Latour, quien evoca la figura de «un nuevo Nietzsche», Sloterdijk escribe justamente para que la cuestión de la eugenesia no sea minimizada, no para hacer su apología ${ }^{16}$. Establecer un código para la antropotecnología es, para el filósofo francés, una necesidad, así como el hecho de reconocer la insuficiencia del humanismo frente a las circunstancias actuales, porque continúa teniendo como horizonte el ideal de un ser humano poderoso, capaz de superar todos los problemas. Consciente de que sería inocente intentar resistirse a la fuerza del bio-poder y al avance de las biotecnologías, solamente con los comités de ética ${ }^{17}$, Latour afirma igualmente que hoy ya no se trata de la eugenesia que fue puesta en práctica en varios países europeos a lo largo del siglo Xx, sino de un uso literal de la metáfora platónica del poder político. Los progresos científicos permiten pensar en eventuales cambios del ser humano, a nivel genético, y con la aprobación irreflexiva del público. «En lugar del lema "el socialismo es los soviéticos más la electricidad”, dice Latour, tenemos “el liberalismo es el platonismo más la genética”»" ${ }^{18}$.

Yves Michaud, por su parte, afirma:

Uno de los méritos de Sloterdijk es que desvela, particularmente en Normas para el parque humano, las relaciones de poder y la gran violencia implicadas en los procesos de domesticación. Ser humano es ser humanizado. Hay quienes humanizan y quienes son humanizados, o que deberían serlo. Unos son criadores y otros son criados. No solamente los criadores imponen un poder, su poder, sino que ellos mismos son seleccionados a través de las relaciones de poder que reproducen. [...] La pregunta, desesperada, que formula Sloterdijk al final de Normas para el parque bumano, es qué sucede cuando no solamente los dioses se han retirado, sino cuando también los sabios han desaparecido, cuando solo nos queda "nuestra escasa sabiduría y nuestros conocimientos a medias". ${ }^{19}$

\footnotetext{
16 «Sloterdijk, l’insupportable», 1999.

17 «Un nouveau Nietzsche», 1999.

18 Ibid. La traducción es mía.

19 «Un des mérites de Sloterdijk est de mettre à nu, tout particulièrement dans les Règles pour le parc humain, les enjeux de pouvoir et la grande quantité de violence présents dans les processus de domestication. Être humain,
} 
La polémica en torno a Normas para el parque bumano, comenzando por las críticas de Habermas, fue la puerta de entrada del posthumanismo en las discusiones intelectuales en Europa. El análisis del momento presente del humanismo se convirtió en una proyección futurista, por la vía de los avances de la tecnociencia en el campo biológico del «perfeccionamiento» del ser humano que propone la ideología transhumanista. Desde el inicio de este milenio, se han multiplicado los debates éticos y filosóficos sobre las posibilidades de transformar o de «mejorar» las características físicas y mentales del ser humano, o incluso de su naturaleza misma, gracias al uso de una biomedicina que ya no diferencia entre una medicina terapéutica y una de «perfeccionamiento».

Las posiciones de filósofos e intelectuales son diversas y podrían organizarse, según los investigadores franceses al origen de la Encyclopédie du transhumanisme et du posthumanisme [Enciclopedia del transhumanismo y del posthumanismo] ${ }^{20}$, en tres grupos: el primero, aquellos que se oponen, los «bioconservadores» como Habermas, Leon Kass (1939-) o Francis Fukuyama (1952-), entre otros. Ellos insisten en las injusticias sociales y las modificaciones tal vez irreversibles en lo que concierne a la naturaleza humana. El segundo, los pensadores liberales, como Jonathan Glover (1941-) en Gran Bretaña y en Francia el especialista en bioética Alex Mauron (1951-), quienes aceptan la idea de la transformación y de la optimización del ser humano sin unirse al discurso cuasi-religioso, profético y utopista del transhumanismo. Finalmente, los transhumanistas mismos, quienes buscan superar la actual condición humana y prometen una vida más larga, feliz y sana, gracias a los beneficios de la tecnociencia. El proyecto de creación de un hombre aumentado, o mejorado, puede ser interpretado como una continuación del humanismo de Las Luces, como un «perfeccionamiento» del humano, o bien como un alejamiento radical del hombre contemporáneo en dirección a un ser nuevo, que tendría pocas cosas en común con su predecesor.

c'est être humanisé. Il y a ceux qui humanisent et ceux qui sont humanisés ou qui devraient l'être. Il y a des éleveurs et des élevés. Non seulement les éleveurs imposent un pouvoir, leur pouvoir, mais ils sont eux-mêmes sélectionnés dans le cadre de relations de pouvoir qu'ils reproduisent. [...] La question désespérante que pose Sloterdijk à la fin des Règles pour le parc humain est de savoir ce qui se passe quand, non seulement, les dieux se sont retirés, mais quand les sages aussi ont disparu, quand il ne nous reste plus que "notre absence de savoir et notre demi-connaissance en toutes choses"». Yves Michaud, Humain, inbumain, trop humain. Réflexions sur les biotechnologies, la vie et la conservation de soi à partir de Peter Sloterdijk, 2006 (89-90). La traducción es mía.

${ }^{20}$ Se trata de Gilbert Hottois, Jean-Noël Missa y Laurence Perbal (7-11). 


\section{Definir el posthumanismo}

Según el filósofo Jean-Michel Besnier, establecer una definición precisa del posthumanismo y de su diferencia con el transhumanismo es una tarea aún pendiente. Ello que se explica por dos razones: la constante evolución de los términos, y los desacuerdos entre las diferentes corrientes que los producen. En su artículo titulado «Posthumain», de la Encyclopédie du transhumanisme et du posthumanisme, afirma:

Entre Nicolas Bostrom (fundador de la World Transhumanist Association [Asociación Transhumanista Mundial]), Max More (al origen del extropianismo [movimiento fundado sobre la fe en un progreso ilimitado de la ciencia y la tecnología]) y Ray Kurzweil (director del Instituto de la Singularidad) la ausencia de consenso es casi total. El primero anuncia que se propone el bienestar y la perpetuación de la humanidad, el segundo, eliminar la entropía que nos lleva a la extinción, y el tercero, preparar la llegada de una Singularidad que dejará a nuestra especie en estado de obsolescencia... En tales condiciones, es difícil aferrarse a algo preciso que podría llamarse "transhumanismo" y que establecería los contornos de lo posthumano. A veces el propósito parece hiperhumanista (perfeccionar al ser humano), a veces cínico (abandonar al humano por otra especie). En el primer caso, el posthumano no sería otra cosa que lo que se llama, cada vez con más frecuencia, "el hombre aumentado". En el segundo, designaría un nuevo ser, producto del surgimiento autorizado por las variaciones inducidas por las manipulaciones tecnológicas. ${ }^{21}$

Si a primera vista el posthumanismo puede ser asimilado con el transhumanismo, o ser percibido como la etapa posterior de un transhumanismo realizado, él puede igualmente asociarse a una orientación diferente, la de la «singularidad tecnológica», según la cual a partir de los campos de la robótica, de la inteligencia artificial y de la biología sintética, los productos fabricados por el ser humano podrían conocer una evolución autónoma y adquirir consciencia de su existencia, o incluso desarrollar una inteligencia e intereses propios.

\section{Un sistema de discursos}

Sin embargo, la «singularidad tecnológica» es apenas una de las orientaciones de los discursos sobre lo posthumano. Esos discursos componen una suerte de sistema, de tipos y

\footnotetext{
${ }^{21}$ «Entre Nicolas Böstrom (fondateur de l'Association mondiale du Transhumanisme), Max More (à l'origine des Extropiens [mouvement fondé sur la foi en un progrès illimité par la science et les techniques]) et Ray Kurzweil (directeur de l'Institut de la Singularité), l'absence d'accord est à peu près totale : le premier annonce qu'il veut réaliser le bien-être et la perpétuation de l'humanité, le second éliminer l'entropie qui nous voue à l'extinction, et le troisième préparer la venue d'une Singularité qui rendra notre espèce obsolète...? Il est difficile dans ces conditions de faire allégeance à quelque chose qui se nommerait «transhumanisme » et qui dessinerait les contours du posthumain: tantôt l'intention semble hyperhumaniste (perfectionner l'homme), tantôt elle paraît cynique (abandonner l'homme pour une autre espèce). Dans le premier cas, le posthumain ne serait guère davantage que ce qu'on nomme de plus en plus communément 'l'homme augmenté' ; dans le second, il désignerait un être inédit, produit de l'émergence autorisée par les variations induites par les manipulations technologiques» (106). La traducción es mía.
} 
de géneros diferentes, ideológico, tecno-científico, político y literario, que es necesario diferenciar y articular para comprender las implicaciones de la entrada del posthumanismo en el campo epistemológico. Propongo distinguir seis, que a veces se cruzan o se superponen: transhumanismo, singularidad tecnológica, cyberpunk, transgresión de fronteras, abhumanismo y antihumanismos, y (post)apocalipsis. Esos discursos tienen en común, en primera instancia, el hecho de interrogar a su manera el estado actual de la humanidad, con el horizonte de lo que podría ser su futuro - o en lo que se está convirtiendo en el presente - a causa de las transformaciones producidas por los avances tecno-científicos, por un lado, y de los movimientos sociales y políticos, por otro. En segunda instancia, esos discursos exponen o imaginan un final del humanismo, o un final de la humanidad, que pueden entenderse como el final de un periodo histórico o de un modelo de organización social, como la transformación radical del ser humano y de algunas de sus características esenciales (físicas y síquicas), o bien como el final físico del ser humano causado por la destrucción de la vida en la Tierra.

\section{El transhumanismo}

En 1957 Julian Huxley (1887-1975), biólogo y antiguo primer director general de la Unesco, fue el primero en utilizar el término transhumanismo, con el propósito de identificar la posibilidad de mejorar al ser humano gracias al uso de la ciencia y la tecnología. El transhumanismo sería una transición del ser humano hacia una versión «perfeccionada» y profundamente diferente de sí mismo. El objetivo, para el ser humano, sería transcender su propia humanidad, tomar las riendas de su propia evolución y modificar su naturaleza según sus intereses. El transhumanismo se presenta como una suerte de «defensa de las tecnologías innovadoras y a menudo como un catequismo para aquellos que quieren creer en el poder regenerador de las máquinas» ${ }^{22}$. No es ni un proyecto ni una utopía social ni una filosofía, sino una forma de autorrealización, un gesto individual, alimentado por ideales que podrían, hipotéticamente, ser alcanzados actualmente o en un futuro próximo: el mejoramiento de capacidades físicas y cognitivas, el fin de la vejez y de las enfermedades y, en un horizonte más lejano, el fin de la muerte misma. La ya mencionada Asociación Transhumanista

\footnotetext{
22 «Plaidoyer favorable à la cause des technologies innovantes et souvent un catéchisme à l'usage de ceux qui veulent croire dans le pouvoir régénérant des machines». Jean-Michel Besnier, «Posthumain» (106). La traducción es mía.
} 
Mundial, fundada en 1998 por Nick Bostrom y por David Pearce (más tarde rebautizada Humanity +), condensa los rasgos más característicos del movimiento transhumanista.

\section{La singularidad tecnológica}

Si el transhumanismo se propone mejorar al ser humano, la singularidad tiene por objetivo mejorar la máquina. El discurso que anuncia esta máquina, o entidad artificial que ha desarrollado una inteligencia, se apoya a menudo en la ley de Moore ${ }^{23}$ y en una «ley» de aceleración del progreso postulada por el futurólogo e inventor estadounidense Raymond Kurzweil (1948-) bajo la fórmula de law of accelerating returns. ${ }^{24}$ La noción de singularidad encuentra sus orígenes al inicio de los años 1950, cuando fue evocada por el matemático y físico húngaro-estadounidense John von Neumann (1903-1957), quien, junto con Alan Turing (1912-1954), fue uno de los pioneros de la informática. Algunos años más tarde, el estadístico Irving J. Good (1916-2009) planteó la posibilidad de que una máquina inteligente, creada por otra máquina, pudiera llevar a cabo su propio desarrollo, su evolución. En los años 1990, el matemático y autor de ciencia ficción Vernor Vinge (1944-) popularizó el concepto en su ensayo «Technological Singularity», en el que previó una evolución exponencial de la tecnología informática que alcanzaría un grado de inteligencia superior al de los humanos. Raymond Kurzweil, figura central de la singularidad, es desde el 2002 director de ingeniería de la empresa Google. Según él, en el año 2045 la evolución de las tecnologías será tal que existirá «una inteligencia no-biológica mil millones de veces más potente que la humana» ${ }^{25}$. Ese momento de transición y de superación es el de la singularidad.

\section{El cyberpunk}

El término fue utilizado por Gardner Dozois en 1984, en su artículo «Science Fiction in the Eighties» con el fin de calificar un subgénero de la ciencia ficción, iniciado por el escritor William Gibson con su novela Neuromancer, y continuado con la obra de otros

\footnotetext{
${ }^{23}$ Postulada en 1965 por Gordon Moore (1929-), doctor en química y en física, y luego reformulada en 1975, la « ley de Moore » es más bien una constatación empírica. Esta ley afirma que el número de transistores de los microprocesadores en una pulgada de silicio se duplica cada dos años. Vulgarizada, esta observación se convirtió en la prueba de que la tecnología duplica su potencia, su capacidad o su velocidad, cada dos años o cada dieciocho meses.

${ }^{24}$ Esta «ley», que puede interpretarse como una prolongación de la de Moore, afirma que la tasa de cambio de los sistemas evolutivos, dentro de los cuales se considera el desarrollo de la tecnología, tiene tendencia a aumentar exponencialmente. Ver: Raymond Kurzweil, The Age of Spiritual Machines, 1999.

${ }^{25}$ Dorian Neerdael, «Singularité», in Gilbert Hottois, Jean-Noël Missa et Laurence Perbal (dir.), L’humain et ses préfixes. Une encyclopédie du transhumanisme et du posthumanisme, (439). La traducción es mía.
} 
autores que publicaban en el fanzine Cheap Thuth: Lewis Shiner, Pat Cadigan, Greg Bear y Bruce Sterling, este último editor de la publicación. Al principio se trata de una reacción virulenta, punk, a la utopía cibernética en boga durante los años 1950 en Estados Unidos. De acuerdo con esta utopía, las tecnologías permitirían la creación de una «aldea global», según las palabras de Marshall McLuhan ${ }^{26}$. Una armonía se instalaría entre los seres humanos y los seres biónicos. Un mundo esterilizado, aséptico, sin violencia y sin crimen, sería entonces posible. El cyberpunk contesta el optimismo y el carácter emancipador de la tecnología para representar, en un futuro próximo, ciudades sobrepobladas, contaminadas, caóticas, en las que nada funciona como estaba previsto, y sobre todo en las que las tecnologías son, simultáneamente, una herramienta del poder para ejercer la represión, y un arma para resistir, para liberarse. El cuerpo humano y la máquina se imbrican, así como lo real y lo virtual. Las relaciones entre los seres humanos son casi inexistentes, o bien han sido reducidas a lo puramente utilitario.

\section{La transgresión de fronteras}

El término frontera evoca un linde, un límite, es así un elemento constitutivo de una definición. Pero una frontera es también un espacio, aquel que se sitúa entre dos elementos. Ese doble significado cumple un papel en la polarización de los discursos sobre la transgresión de las fronteras humanas. En su obra Notre bumanité, el filósofo francés Francis Wolff expone lo que llama un «desvanecimiento de fronteras» que implica la pérdida de la especificidad de lo humano:

Con el desvanecimiento de fronteras en el estudio del hombre parece desaparecer toda su especificidad, por la cual se distinguía de su Otro - o mejor, de sus Otros. En la antigüedad, con Aristóteles principalmente, los hombres eran definibles por su diferencia con las dos "faunas" que los rodeaban, los animales y los dioses: lo que tenían en común con unos, los oponía a los otros, y lo que los distinguía de unos, los ligaba a los otros. En la época clásica, en particular con Descartes, el hombre podía definirse gracias a una doble oposición: por un lado con respecto a Dios, cuyo entendimiento, al contrario del suyo, es infinito, pero con el cual comparte la potencia infinita de la voluntad; y por otro lado con el animal, del que se diferencia por el pensamiento, pero con el cual comparte un cuerpo mecánico, vivo y mortal. A partir de lo que se ha llamado el "desencantamiento del mundo", por el cual Dios se ausentó progresivamente de la explicación de los fenómenos naturales, al hombre ya no le quedaba más que un Otro para definirse, el animal. ${ }^{27}$

${ }^{26}$ Understanding Media: The Extensions of Man, 1964.

${ }^{27}$ «Avec l'effacement des frontières dans l'étude de l'homme semble disparaitre toute spécificité de l'homme, par laquelle il se distinguait jadis de son Autre - ou plutôt de ses Autres. Dans l'Antiquité, chez Aristote en particulier, les hommes étaient définissables par différence avec les deux "faunes" qui les entouraient, les animaux et les dieux : ce qu'ils avaient en commun avec les uns les opposait aux autres, et ce qui les distinguait 
Esta última categoría de diferenciación se revela, dice más adelante Wolff, igualmente insuficiente, ya que también el animal fusiona con el humano (163). Un ejemplo del desvanecimiento de esas fronteras se encuentra a partir de las perspectivas abiertas por la etología moderna desarrollada en los años 1940. Por otra parte, y de forma paralela, otras fronteras son revisitadas, algunas gracias a las tecnociencias (real/virtual, humano/máquina). La transgresión de esas fronteras configura nuevos espacios, intersticios críticos y de intercambio, donde las especificidades de lo humano, como sujeto y como objeto, parecen borrarse.

\section{Abhumanismo y antibumanismos}

En 1955, el filósofo francés Jacques Audiberti propuso el concepto de abhumanismo, que definió de la siguiente manera:

Es el hombre aceptando perder de vista que es el centro del universo. ¿Cuál es el propósito del abhumanismo? Aminorar el sentimiento de nuestra eminencia, de nuestra preponderancia y de nuestra excelencia con el fin de restringir, al mismo tiempo, la gravedad sacrílega y la venenosa ebullición de insultos y de sufrimientos que padecemos. [...]

La única proposición que el abhumanismo puede hacer, es el final de la especialidad humana. Nuestra literatura, tradicionalmente soberana y popular, si continúa ocupándose solamente de lo humano, modelo antiguo, corre el riesgo de condenarse..$^{28}$

El abhumanismo, que es tanto teórico como simbólico, toma en cuenta las reacciones contra la especificidad humana, y puede por ejemplo adoptar la forma del antiespecismo y proponer el establecimiento de una comunidad ampliada, compuesta por seres humanos y no-humanos sin diferenciaciones jerárquicas. En ese sentido, los discursos ecologistas radicales o otros que promueven el veganismo le pueden ser asociados. Sin embargo, esta ampliación propuesta por el abhumanismo no es necesariamente compartida

des uns les liait aux autres. À l'âge classique, chez Descartes en particulier, l'homme pouvait se définir par une double opposition : avec Dieu, d'une part, dont l'entendement, au contraire du sien, est infini, mais avec qui il partage la puissance infinie de la volonté ; avec l'animal, d'autre part, dont il se distingue par la pensée, mais avec lequel il partage un corps mécanique, vivant et mortel. À partir de ce qu'on a appelé, à la suite de Max Weber, le "désenchantement du monde", par lequel Dieu s'est progressivement absenté de l'explication des phénomènes naturels, l'homme n'avait plus qu'un Autre pour se définir : l'animal» (143). La traducción es mía. 28 «C'est l'homme acceptant de perdre de vue qu'il est le centre de l'univers. Quel est le propos de l'abhumanisme ? Amoindrir le sentiment de notre éminence, de notre prépondérance et de notre excellence afin de restreindre, du même coup, la gravité sacrilège et la vénéneuse cuisson des injures et des souffrances que nous subissons. [...] La seule proposition que puisse faire l'abhumanisme sera qu'on en finisse avec le spécialisme humain. Notre littérature, ci-devant royale et boulevardière, si elle continue à ne s'occuper que de l'humain ancien modèle, elle risque fort de se condamner.» L'Abbumanisme, (19, 35). La traducción es mía. 
por los antihumanismos contemporáneos. Es posible además diferenciar un antihumanismo jerárquico de uno pesimista.

El antihumanismo jerárquico contesta una forma de jerarquía al seno de una comunidad humana organizada según un modelo humanista, sin implicar necesariamente la inclusión del Otro no-humano. Para la filósofa Rosi Braidotti (1954-), el humanismo es la universalización arbitraria e histórica de una determinación específica, en este caso europea, blanca y masculina. El establecimiento de normas y de parámetros sociales, políticos y culturales que corresponden con esta determinación, así como su presentación en tanto medida universal, se acompañan de la idealización producto de la marginalización de aquellos que no corresponden física, síquica o culturalmente con ese modelo. Movimientos feministas radicales, antirracistas o postcolonialistas pueden ser asociados a esta crítica.

En el antihumanismo pesimista, el prefijo anti no tiene el mismo valor que en el caso precedente. Si en el antihumanismo jerárquico se trata de oponerse a un humanismo jerárquico, no es la intención aquí posicionarse contra un humanismo pesimista, sino oponer a la esperanza y la fe humanistas en lo humano, el pesimismo como alternativa crítica. Es posible rastrear su origen en la crítica de Heidegger y el «¿para qué?» de la celebración y la sobreelevación de lo humano. ${ }^{29}$ En otros términos, el pesimismo antihumanista permite medir la brecha entre un ideal del proyecto humanista y la incapacidad humana para alcanzarlo. Se marca así una superación de lo ideal hacia la transformación de lo real.

\section{(Post)apocalipsis}

En tanto género literario, el apocalipsis está muy lejos de limitarse al Apocalipsis de Juan en la Biblia ${ }^{30}$. No obstante, si bien esos relatos son abundantes en el seno de las comunidades judía y cristiana, poseen en general elementos comunes, dentro de los cuáles, según Élian Cuvillier, uno de los más característicos es la idea de que la destrucción es necesaria, que «la llegada de un mundo nuevo implica obligatoriamente la condena y la destrucción del mundo antiguo» ${ }^{31}$. En lo que se refiere a la forma, los relatos utilizan a

\footnotetext{
${ }^{29}$ Ver en este texto la página 447.

30 «El género apocalíptico se propagó en la región mediterránea del siglo II aC. al siglo II dC. La importancia, la frabilidad y la autoridad del Apocalipsis de Juan en la historia son así, principalmente, debidas al hecho de que el texto se encuentra en la Biblia». Geert Van Oyen, «Arrêt sur image(s) dans l'Apocalypse de Jean», 2012 (12). La traducción es mía.

31 «La venue du monde nouveau passe obligatoirement par la condamnation et la destruction du monde ancien». Élian Cuvillier, L'Apocalypse... c'était demain. Protestations d'espérance au cæur du Nowveau Testament, 1987, (72). La traducción es mía.
} 
menudo un lenguaje simbólico que descalifica la lectura literal. El posthumanismo en sus formas apocalíptica o post-apocalíptica, es la posibilidad de imaginar el momento inmediatamente anterior, el «antes», o bien el «después» de esta destrucción, casi total, del ser humano.

Esa desaparición parcial puede ser material (exterior) o íntima, espiritual (interior). En los dos casos, tiene lugar una confrontación fundamental: por el desvelamiento («apocalipsis» según su etimología) de los personajes en situaciones fuera de lo común, tiene lugar una profunda revelación de sentimientos y de creencias. El post puede aquí implicar la fundación de nuevos criterios, de nuevas bases para la existencia, pero solamente como consecuencia de una mirada introspectiva y de un examen personal, al momento presente, sobre las responsabilidades y los responsables de la extinción.

Esos discursos, desarrollados principalmente a partir de la segunda mitad del siglo XX, se imbrican y componen un sistema móvil y en permanente construcción. La entrada del posthumanismo al campo epistemológico al inicio del siglo XXI adquiere el carácter, por un lado, de una observación y una crítica del mundo contemporáneo, por otro, el de una evaluación retrospectiva del siglo Xx.

La relación entre la literatura, el cine y el posthumanismo es dialéctica y se configura en tres etapas. La primera, la divulgación del posthumanismo a través de la literatura y del cine. La ciencia ficción literaria y cinematográfica han sido de una importancia decisiva para los orígenes del transhumanismo y de la singularidad tecnológica, pero también para su divulgación, asimilación y aceptación de la parte del público general. La segunda, la literatura y el cine pueden funcionar como una suerte de laboratorio para el posthumanismo. Las cuestiones filosóficas, éticas, políticas e incluso técnicas y estéticas de las manifestaciones del posthumanismo son ampliamente exploradas por la literatura y el cine. Un poco a la manera de una herramienta de prospectiva, las representaciones artísticas del posthumanismo pueden simultáneamente imaginar y reflexionar sobre las posibles consecuencias de una transformación física o síquica del ser humano, sobre el desarrollo de la inteligencia artificial y de su lugar en la sociedad, sobre los efectos a corto plazo de un desarrollo desmesurado e invasivo de la tecnología y su relación con el sistema capitalista, sobre otras posibilidades de relación entre los humanos y los animales, sobre los fenómenos que pueden provocar la 
destrucción o una profunda modificación de la vida humana y de la necesidad de recomenzar una sociedad, etc. La literatura y el cine pueden igualmente ser un arma política de protesta o de reivindicación para quienes han sido excluidos de una concepción particular del humanismo como modelo, o para representar una comunidad inclusiva y no jerárquica entre los seres humanos y los no-humanos. Finalmente, en la tercera etapa, el posthumanismo puede girarse hacia la literatura y el cine para convertirse en una herramienta epistemológica. De esta manera, más allá de los géneros como la ciencia ficción o la contestación política, se trata menos de abordar las obras, literarias y cinematográficas, en las que se representan manifestaciones del posthumanismo, que de un posthumanismo que observa las obras. El objetivo es concebir al posthumanismo no como un filtro sino como un horizonte, capaz de resaltar el valor específicamente literario y cinematográfico de las obras, sin reducirlas ni a la representación de un tema ni a una propuesta axiológica. 


\section{BIBLIOGRAFÍA}

Atlan, Henri. (1999): «La biologie de demain n’est pas l'eugénisme nazi» [entretien], Le Monde des débats, novembre.

Audiberti, Jacques. (1955): L'Abhumanisme, Paris, Gallimard.

Besnier, Jean-Michel (2015): «Posthumain», en Gilbert Hottois, Jean-Noel Missa y Laurence Perbal (dir.), L’humain et ses préfixes. Encyclopédie du transhumanisme et du posthumanisme, Paris, Librairie Philosophique J. Vrin.

Borges, Jorge Luis (2019 [1941]): «Tlön, Uqbar, Orbis Tertius», en Cuentos completos, Barcelona, Lumen.

Cuvillier, Élian (1996 [1987]): L'Apocalypse... c'était demain. Protestations d'espérance au cour du Nouveau Testament, Aubone, Éditions du Moulin.

Dozois, Gardner (1984): «Science Fiction in the Eighties», Washington Post, 30 de diciembre.

Foucault, Michel (2001 [1966]): «L'homme est-il mort? (entretien avec C. Bonnefoy)», en Dits et écrits 1954-1988, Paris, Gallimard.

Foucault, Michel (1968 [1966]): Las palabras y las cosas. Una arqueología de las ciencias humanas, traducido del francés (Les Mots et les Choses. Une archéologie des sciences humaines) por Elsa Cecilia Frost, Buenos Aires, Siglo XXI.

Habermas, Jürgen (2002): L'avenir de la nature bumaine. Vers un engénisme libéral?, traducido del alemán (Die Zukunft der menschlichen Natur. Auf dem Weg zu einer liberalen Eugenike?) par Christian Bouchindhomme, Paris, Gallimard.

Hottois, Gilbert, Jean-Noel Missa y Laurence Perbal (dir.) (2015): L'bumain et ses préfixes. Encyclopédie du transhumanisme et du posthumanisme, Paris, Librairie Philosophique J. Vrin.

Kurzweil, Raymond (1999): The Age of Spiritual Machines, New York, Viking Press.

Latour, Bruno (1999): «Sloterdijk, l’insupportable», Le Monde des débats, novembre.

Latour, Bruno (1999): «Un nouveau Nietzsche», Le Monde des débats, novembre.

McLuhan, Marshall (1964): Understanding Media: The Extensions of Man, New York, McGraw Hill.

Michaud, Yves (2006): Humain, inhumain, trop bumain. Réflexions sur les biotechnologies, la vie et la conservation de soi à partir de Peter Sloterdijk, Paris, Climats. 
Nietzsche, Friedrich (2003 [1885]): Así babló Zaratustra. Un libro para todos y para nadie, traducido del alemán (Also Sprach Zarathoustra. Ein Buch für Alle und Keinen) por Andrés Sánchez Pascual, Madrid, Alianza Editorial.

Nietzsche, Friedrich (2005 [1873]): Sobre verdad y mentira en sentido extramoral, traducido del alemán (Über Warheit und Lüge im außermoralischen Sinn) por Luis Manuel Valdés Villanueva, Madrid, Tecnos.

Nietzsche, Friedrich (2012 [1872].): El nacimiento de la tragedia o Grecia y el pesimismo traducido del alemán (Die Geburt der Tragödie aus dem Geiste der Musik) por Andrés Sánchez Pascual, Madrid, Alianza Editorial.

Sloterdijk, Peter (2002): «Le scandaleux» [entrevista con Elisabeth Lévy], Journal Le Point, 14 février.

Sloterdijk, Peter (2006 [1999]): Normas para el parque bumano. Una respuesta a la Carta sobre el humanismo de Heidegger [traducido del alemán (Regeln für den Menschenpark. Ein Antwortschreiben ₹и Heideggers Brief über den Humanismus) por Teresa Rocha Barco], Madrid, Siruela.

Updike, John (1999): «On the Edge of the Post-human. Night Train by Martin Amis. 147 pp. Jonathan Cape, 1997», en More Matter. Essays and criticism, London, Hamish Hamilton.

Van Oyen, Geert (2012): «Arrêt sur image(s) dans l'Apocalypse de Jean», en Arnaud JoinLambert, Serge Goriely et Sébastien Fevry (dir.), L’imaginaire de l’apocalypse au cinéma, Paris, L'Harmattan.

Vinge, Vernor (1993): «Technological Singularity», en VISION-21, San Diego, San Diego State University. (https://mindstalk.net/vinge/vinge-sing.html) (último acceso: $4 / 5 / 2020)$.

Wolff, Francis (2010): Notre bumanité, Paris, Fayard. 


\section{Carlos Tello}

Carlos Tello es doctor en Histoire et Sémiologie du Texte et de l'Image de l'Université de Paris. Trabaja sobre literatura comparada contemporánea y cine, principalmente desde una perspectiva posthumanista, y sobre literatura y cine en Latinoamérica y España. Enseña actualmente en l’Université Paris-Est Créteil.

Contact information: email: carlosetello@gmail.com

Orcid : https://orcid.org/0000-0002-5682-4370 